\title{
Central Dopaminergic Pathways in Hemiparkinsonism Examined by Positron Emission Tomography
}

\author{
E.S. Garnett, C. Nahmias and G. Firnau
}

\begin{abstract}
F}\right] 6$-fluoro-L-dopa and positron emission tomography has been used to study intracerebral dopamine distribution in five control subjects and six patients with hemiparkinsonism. In the control subjects striatal, frontal and cingulate accumulations were clearly seen. In addition ${ }^{18} \mathrm{~F}$ concentrated in the region of the insula and the parietal lobe.

In the patients striatal accumulation ${ }^{18} \mathrm{~F}$ was reduced in the contralateral striatum, especially in the putamen. The uniformity of distribution of ${ }^{18} \mathrm{~F}$ in the striatum on the side of the parkinsonian signs was also irregular. This finding is consonant with the suggestion that intracerebral compensatory mechanisms prevent the manifestation of intracerebral dopamine deficiency from becoming obvious until a late stage of the disease.
\end{abstract}

RÉSUMÉ: Le $\left[{ }^{18} \mathrm{~F}\right]$-6-fluoro-L-dopa et la tomographie à émission de positrons ont été utilisés pour étudier la distribution de la dopamine au niveau du cerveau de cinq sujets normaux et de six sujets souffrants de la maladie de Parkinson unilatérale. Chez le sujet normal, la fixation du $\left[{ }^{18} \mathrm{~F}\right]$ est clairement démontrée dans le corp strié, le lobe frontal et la circonvolution cingulate, et aussi dans la region de l'insula et le lobe pariétal.

Chez le sujet souffrant de la maladie de Parkinson unilatérale, une diminution de la fixation du $\left[{ }^{18} \mathrm{~F}\right]$ a été identifiée dans le corp strié contralatéral, particulièrement dans le putamen. La distribution du $\left[{ }^{18} \mathrm{~F}\right]$ dans le corp strié ipsilateral est aussi irrégulière. Ces résultats sont concordants avec la thèse que des mécanismes intracérébraux compensatoires retardent la manifestation des symptomes résultants d'une carence de dopamine cérébrale jusqu'à un stade avancé de la maladie.

Can. J. Neurol. Sci. 1984; 11:174-179

A loss of cells from the Zona compacta of substantia nigra and a consequent reduction in striatal dopamine concentration characterise Parkinson's disease [Hornykiewicz, 1982]. Such definitive measurements can only be made on autopsy material. Striatal dopaminergic afferents account for approximately $10 \%$ of all neurones impinging on the striatum [Hokfelt and Ungerstedt, 1974] so that even a massive reduction in their number cannot be detected by computerized axial tomography. With the advent of positron emission tomography, using $\left[{ }^{18} \mathrm{~F}\right]$ 2-fluoro-2-deoxyD-glucose, or oxygen-15 claims for disordered cerebral metabolism in Parkinson's disease have been made [Lenzi et al., 1977; Leenders et al., 1983; Rougemont et al., 1983]. However, there is still no concensus. Careful autoradiographic studies using $\left[{ }^{14} \mathrm{C}\right]$ deoxyglucose in rats [Wooten and Collins, 1981] show that glucose consumption in globus pallidus is increased ipsilaterally when the substantia nigra is destroyed on one side by direct injection of 6-hydroxydopamine.

It has recently become possible to visualize dopamine directly in the human brain. This has been done by positron emission tomography using $\left[{ }^{18} \mathrm{~F}\right]$ 6-fluoro-L-dopa as an analogue of dopa [Garnett et al., 1983]. The purpose of this article is to describe the anatomy of the intracerebral dopaminergic pathways, as depicted by $\left[{ }^{18} \mathrm{~F}\right]$ fluorodopa, and to compare our findings in control subjects with those derived from a small group of individuals suffering from hemiparkinsonism.

\section{Material aNd Methods}

Six patients, aged 47 to 66 years with hemiparkinsonism and five control subjects aged from 25 to 50 years were studied. The parkinsonian patients were all male and fortuitously all had predominantly left sided symptoms: one of the patients was left handed. Tremor was the presenting symptom in five of the six patients and had been present from two to six years. Hypokinesia was demonstrated in all patients and was the presenting feature in one. Only one patient was taking antiparkisonian drugs (Sinemet) at the time of the study. The control subjects were healthy members of the laboratory staff.

$\left[{ }^{18} \mathrm{~F}\right] 6$-fluoro-L-dopa was prepared from accelerator produced ${ }^{18} \mathrm{~F}$ [Firnau et al., 1981]. It was injected intravenously 1 hour before an individual's head was examined in the tomograph. An individual sat quietly for the hour between injection and examination.

Because the striata can be asymetrically disposed within the brain a series of at least five sequential slices were examined. Each slice was $1.6 \mathrm{~cm}$ thick; it overlapped its predecessor by $0.5 \mathrm{~cm}$ and it was oriented approximately $10^{\circ}$ above the orbitomeatal line. The McMaster positron tomograph that was used for these studies has a spatial resolution of $7 \mathrm{~mm}$, Full Width at Half Maximum, in the plane [Nahmias et al., 1983]. 


\section{RESULTS}

Figures 1 and 2 illustrate the distribution of ${ }^{18} \mathrm{~F}$ in a normal brain. The sequence of tomographic slices was collected over 90 min during which time there was little change in tissue concentration of ${ }^{18} \mathrm{~F}$. Radioactivity is seen in the temporalis muscles in all slices. The striatum is clearly seen in five of the eight slices. The lowest striatal slice 1(b) shows nucleus accumbens; slices 1(d), 2(a) and 2(b) show the putamen as an immediate posterior relation of the head of the caudate; slice 2(c) shows the uppermost part of the head of the caudate. The lowest slice of all, 1(a), shows the anterior poles of the temporal lobes flanking the cavernous sinus which at 60 min contains no measurable fluorine-18 activity.

The uppermost two slices 2(c) and 2(d) show isotope in the frontal lobes and in the anterior part of the cingulate gyrus. Apart from the striatal accumulation of radioactivity a striking feature of this study was the accumulation of fluorine- 18 in the frontal lobe, the region of the insula, lateral to striatum, and in the parietal lobe. Occipital activity was always conspicuously low.

Figure 3 shows typical tomographic slices obtained from each of 4 of the 6 patients suffering from hemiparkinsonism. In all cases accumulation of ${ }^{18} \mathrm{~F}$ in the right (contralateral) putamen is reduced or absent. When compared to normals there is also a reduction in the accumulation of activity in the head of the caudate. Although this is a preliminary study we have a distinct impression that the accumulation of isotope in the ipsilateral striatum is less uniform than in the control subjects. There is no apparent difference in the distribution of cortical radioactivity.

\section{Discussion}

As with any technique that uses external probes to localise and quantitate the distribution of radioactively labelled molecules within an organism it must be assumed that the label, in this case fluorine-18, remains attached to the molecule of interest and does not change its biological properties. There is ample evidence that $\left[{ }^{18} \mathrm{~F}\right]$ fluorodopa fulfills these criteria [Garnett et al., 1983]. However we do not yet know which of the intracerebral metabolites of dopa is carrying the label an hour or more after it has been injected. In rhesus monkeys half of the fluorine-18 that is present in the striatum at one hour can be discharged with reserpine [Garnett et al., 1983]. This suggests that part of the radioactivity is in the form of fluorodopamine which is known to be formed by decarboxylation of fluorodopa [Firnau et al., 1975]. It is unlikely that much of the ${ }^{18} \mathrm{~F}$ activity, is due to the major metabolite of dopa, homovanillic acid, [HVA] because the half clearance time for intracerebral HVA is only about 10 minutes [Wiesel et al., 1973]. Fluorodopa is cleared very rapidly from the blood so that the blood itself cannot sustain a feed of radioactivity to the brain. On balance it would seem that most of the ${ }^{18} \mathrm{~F}$ in the brain one to two hours after an injection of $\left[{ }^{18} \mathrm{~F}\right]$ fluorodopa is $\left[{ }^{18} \mathrm{~F}\right]$ fluorodopamine. At autopsy striatal dopamine concentration exceeds that of the cortex thirtyfold [Lloyd and Hornykiewicz, 1972]. In this present study the ratio of striatal to cortical activity is only $3: 1$. This reduced relative concentration may reflect delayed vesicular storage of newly formed fluorodopamine in the striatum. It may also be due to a more rapid metabolism of fluorodopa in the cortex with subsequent loss of cortical radioactivity as $\left[{ }^{18} \mathrm{~F}\right]$ fluoro-HVA. There is some evidence to support the latter hypothesis [Hornykiewicz, O., Personal
Communication]. It is also generally believed that tyrosine hydroxylase is the rate limiting enzyme in the synthetic chain leading to dopamine. Because the administration of fluorodopa bypasses this step it might be argued that any local intracerebral accumulation of fluorine-18 merely reflects the local activity of the next enzyme in the synthetic chain, viz. aromatic acid decarboxylase. If this were the explanation a ratio of striatal to cortical ${ }^{18} \mathrm{~F}$ activity of $12: 1$ would be predicted on the basis of the regional distribution of aromatic $\mathrm{L}$-amino acid decarboxylase reported by Lloyd and Hornykiewicz (1972).

From an anatomical standpoint the accumulation of fluorine-18 in the opercular regions was unexpected as was the posterior extension of what we believe to be dopaminergic activity into the parietal lobe. Some accumulation of labelled fluorodopa in the diffusely distributed noradrenergic cortical system cannot be excluded. If this were the explanation for the opercular activity a similar accumulation would be expected in the occipital lobes.

In the hemiparkinsonian patients the accumulation of ${ }^{18} \mathrm{~F}$ was reduced in the contralateral putamen. This observation could be corroborated in several sequential tomographic slices. The accumulation of ${ }^{18} \mathrm{~F}$ in the contralateral caudate was al so reduced but, qualitatively, to a much lesser extent than in the putamen. Although the alterations in striatal ${ }^{18} \mathrm{~F}$ accumulation were primarily on the side opposite to the parkinsonian signs the ipsilateral striatum could also be distinguished from normal; its accumulation of ${ }^{18} \mathrm{~F}$ was never as intense or as uniform as in the control subjects.

These findings represent the first direct demonstration, during life, of a disturbance of intrastriatal dopamine metabolism in Parkinson's disease. A loss of dopamine, predominantly affecting the putamen, has been noted before in autopsy material, (Hornykiewicz, 1980) and Lee et al. (1978) found that the specific binding of ${ }^{3} \mathrm{H}$-apomorphine was significantly reduced in the putamen of parkinsonian patients who had not received L-dopa therapy. These same authors noted an increase in specific binding of ${ }^{3} \mathrm{H}$-haloperidol in the putamen and attributed their findings to denervation supersensitivity. Our results would also be expected from a reduced number of dopaminergic terminals in the putamen. Compared to the data usually reported from autopsy studies, our patients were relatively young, (mean age, 54 years) and had displayed parkinsonian signs for a relatively short time (mean 3 years). They were thus studied at an early stage in their disease and while in good health. All were employed in their usual jobs and two played racquet games regularly. Tremor of the contralateral hand and arm was the most constant and striking sign in our patients and it might be tempting to ascribe this sign to a deficiency of dopaminergic activity in the putamen. However one patient who was primarily hypokinetic and had no tremor could not be distinguished from the other patients on the basis of the fluorodopa study. An abnormal accumulation of ${ }^{18} \mathrm{~F}$ was also present on the side of the parkinsonion signs. Again, it was the area of the putamen that was most involved. This biochemical abnormality would seem to antedate the onset of physical signs. Our findings are thus consonant with the notion that the physical signs of Parkinson's disease develop relatively late in the natural history of the disease and represent a state of striatal decompensation. What we do not yet know is whether the reduced accumulation of ${ }^{18} \mathrm{~F}$ fluoro-dopa in the putamen is due to a loss of dopaminergic neurones or whether it represents a functional abnormality of these cells at a relatively early stage of the disease. 


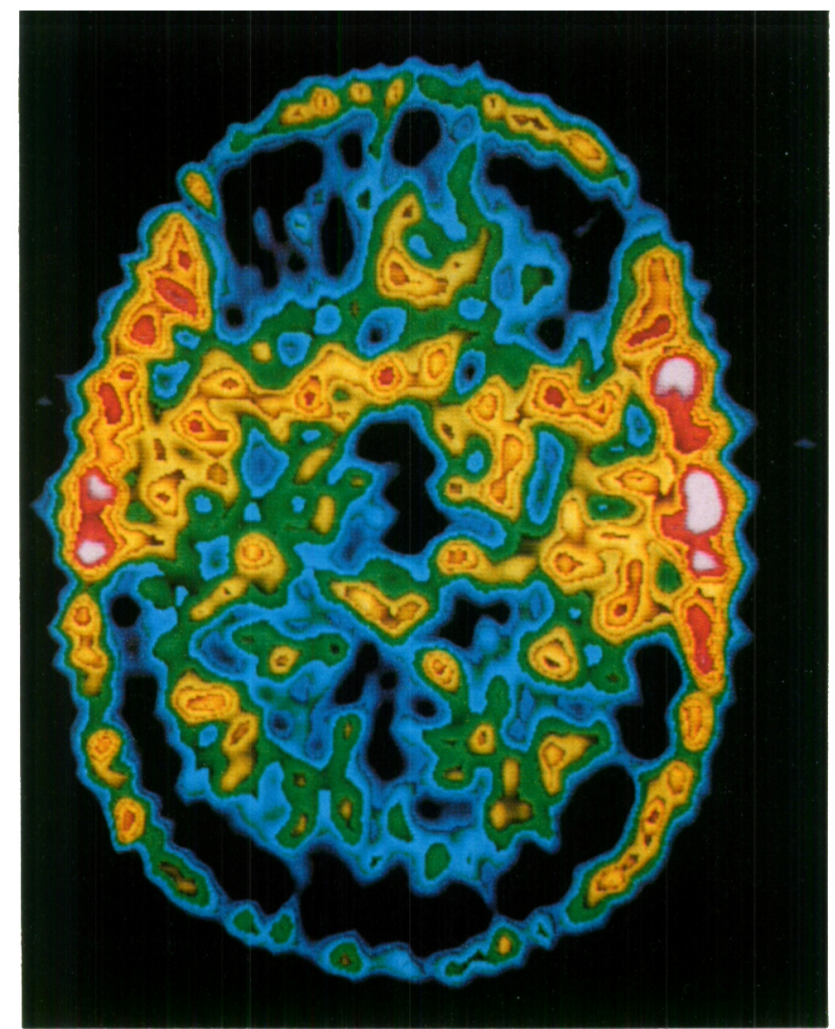

A

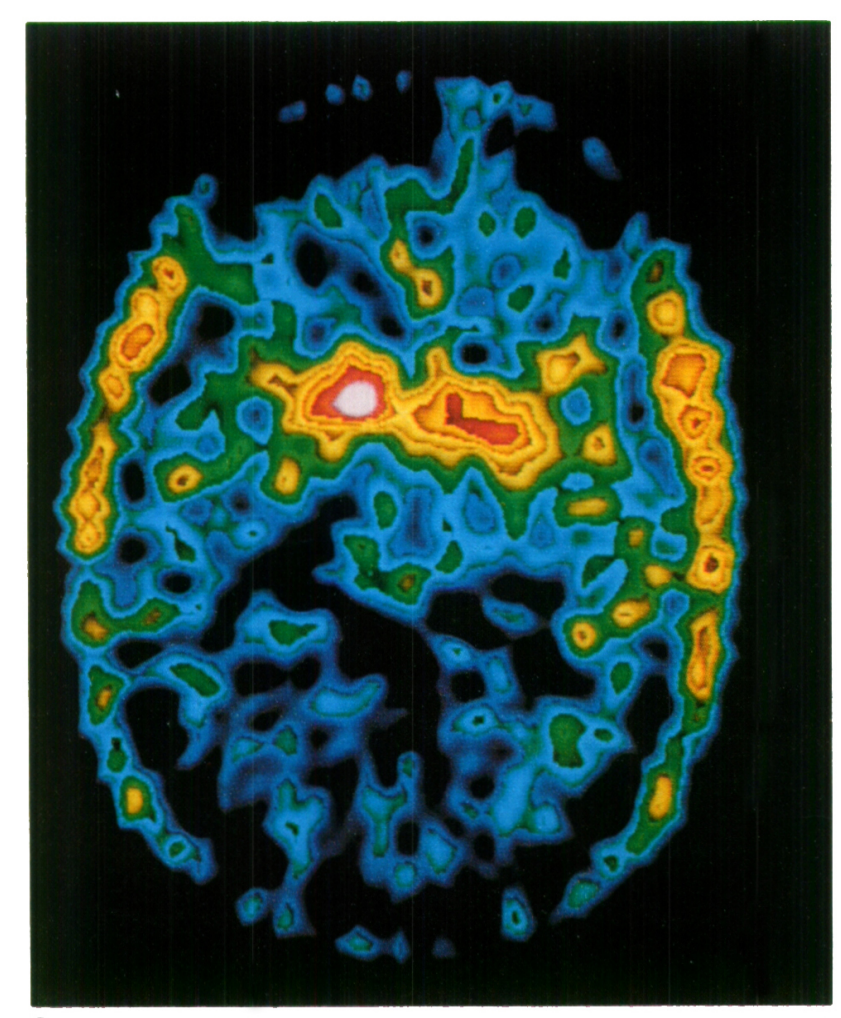

$\mathrm{C}$

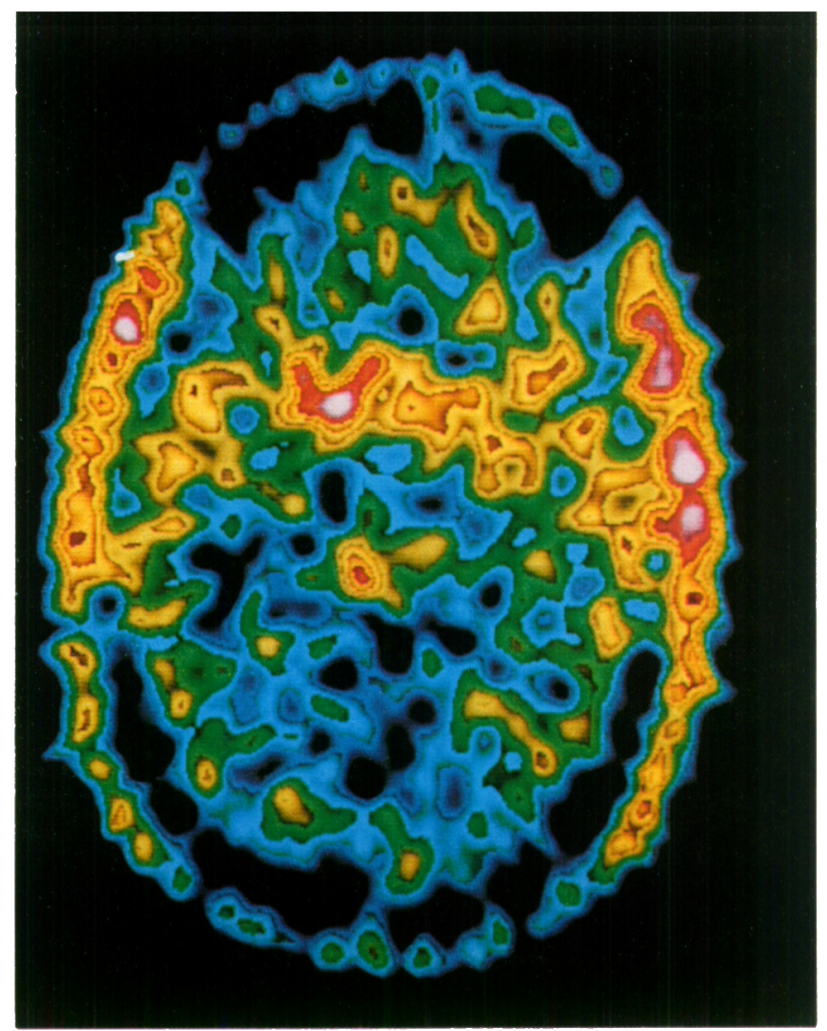

B

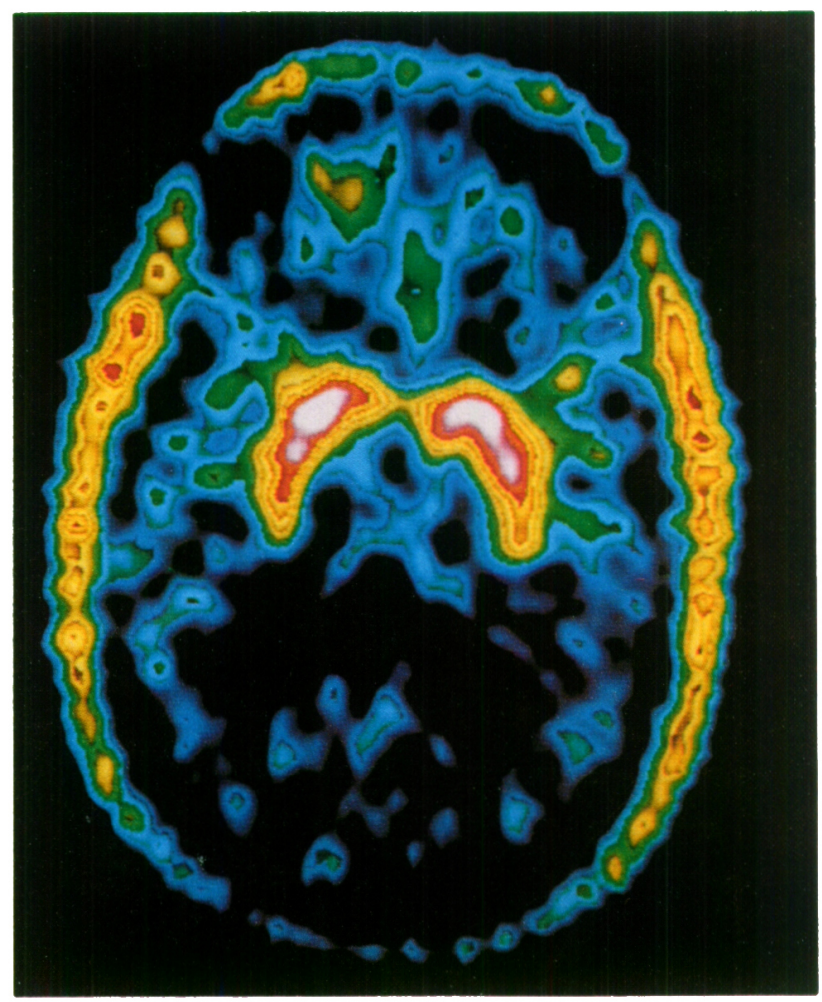

D

Figure I - Tomographic slices of normal brain from a single individual obtained approximately 1 hour after an I.V. injection of $3.0 \mathrm{mCi} I^{I 8} \mathrm{~F} / 6$-fluoro-L-dopa. All slices are parallel to a plane orientated $10^{\circ}$ above the orbito meatal line. The lowest slice, (A), transects the cavernous sinus which appears black in the centre of the picture. The next slice up $(B)$ contains nucleus accumbens and posterior to it the most rostral part of substantia nigra. Slice (C) contains the heads of the caudate and slice $(D)$ the whole striatum.

All of the figures are colour coded with purple representing the most intense accumulation of ${ }^{\prime 8} \mathrm{~F}$ followed by the reds, yellows, greens and blues. The most peripheral activity in this and the subsequent figures is due to radioactivity in the temporalis muscles. 


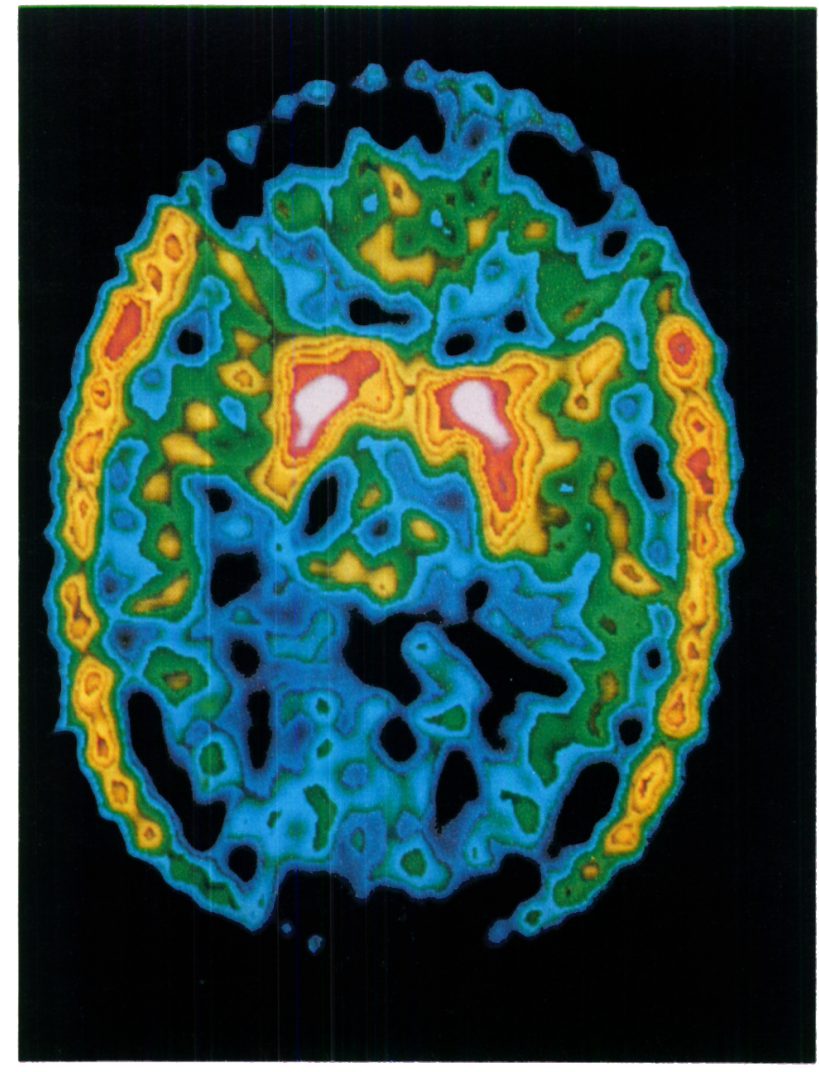

A

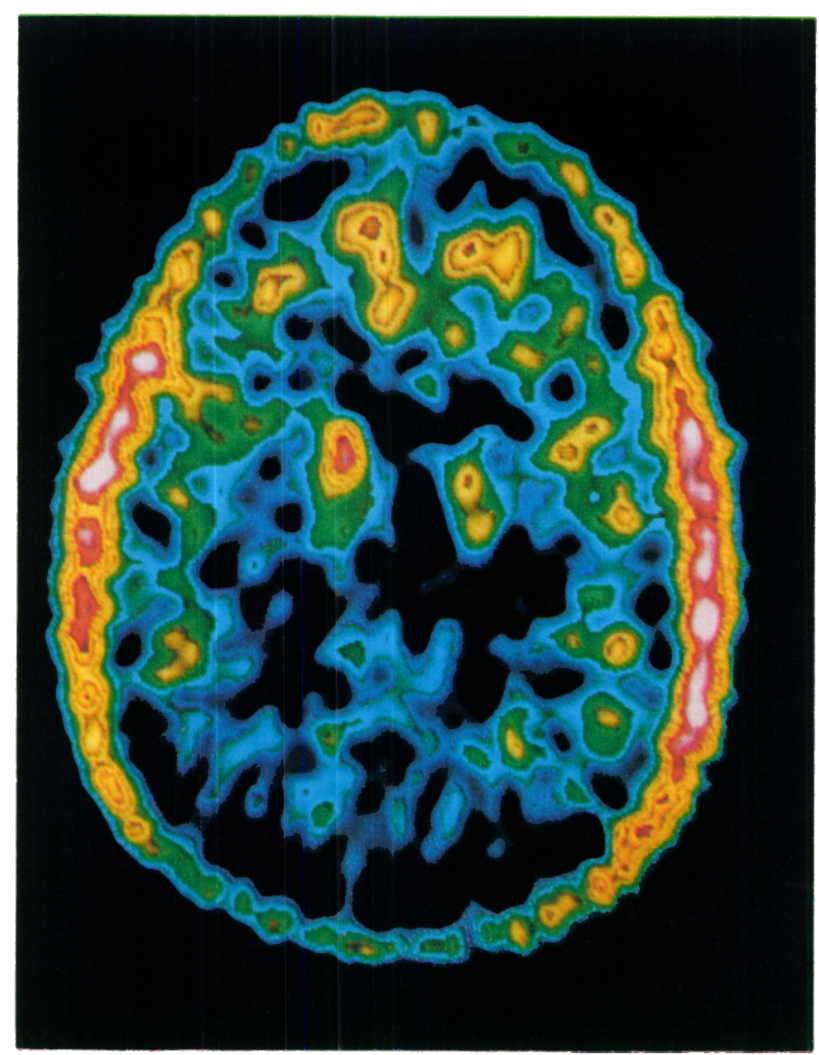

$\mathrm{C}$

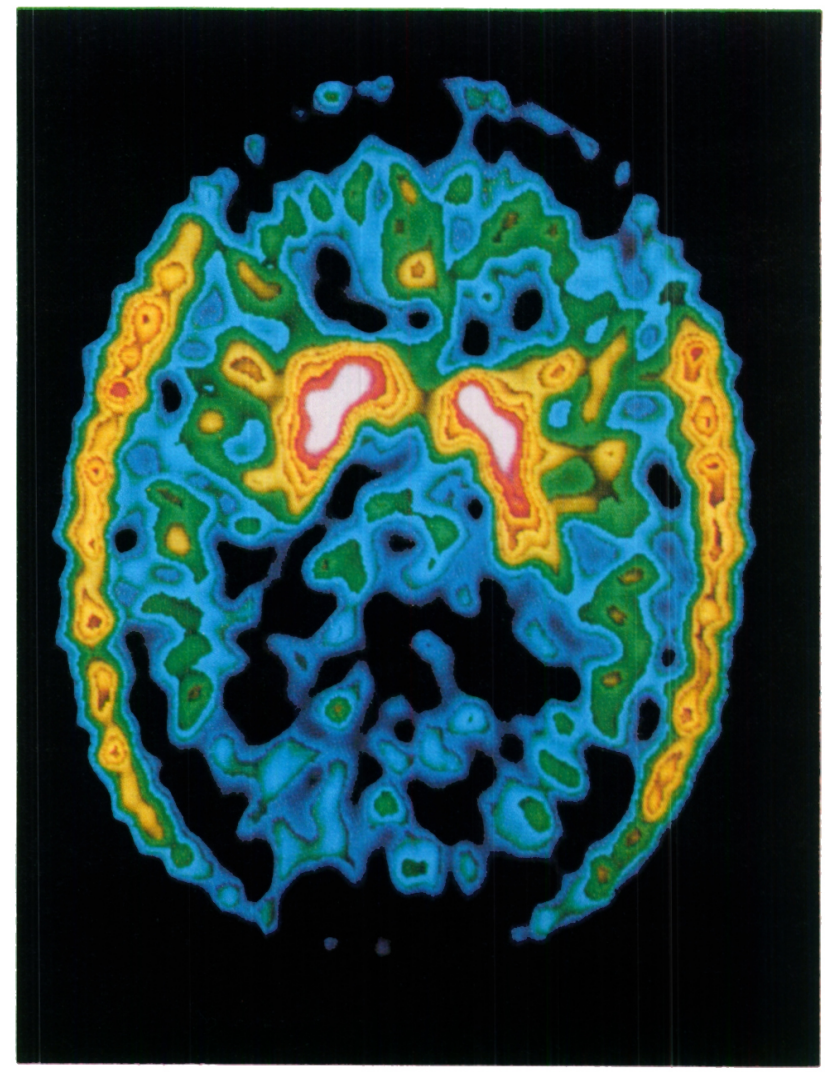

B

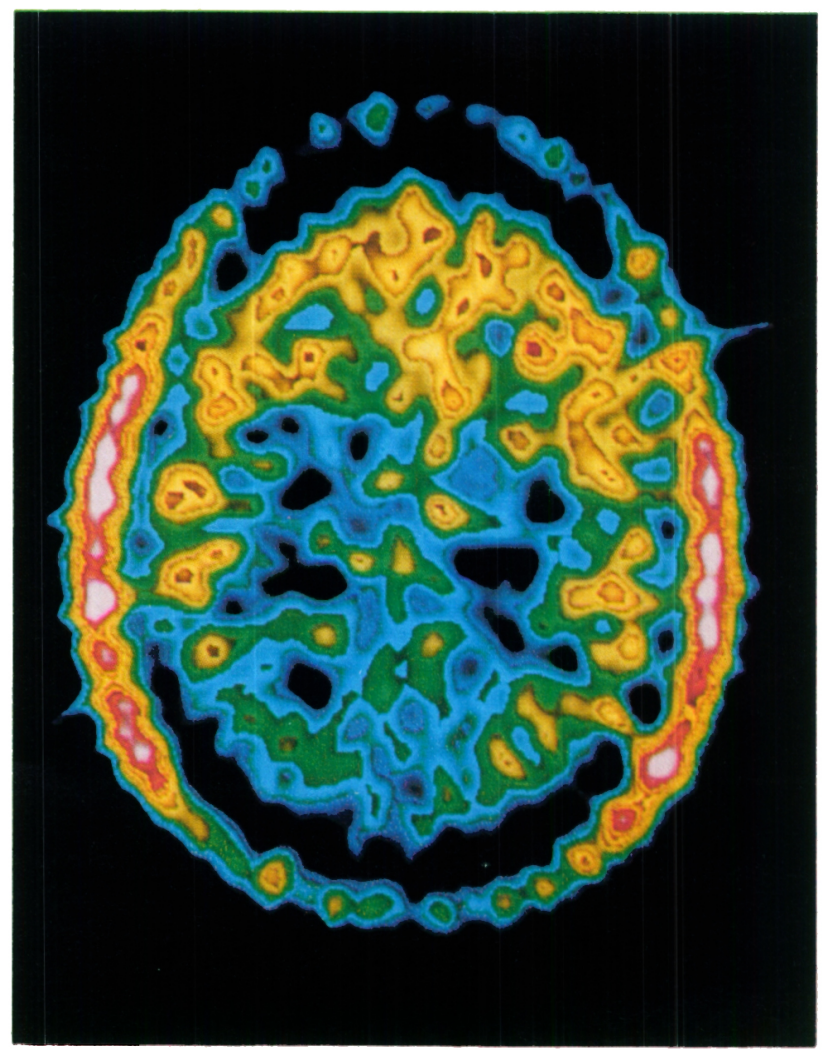

$\mathrm{D}$

Figure $2-(A)$ and $(B)$ show the whole stritum and $(C)$ shows the upper part of the heads of the caudate. Slices $(C)$ and $(D)$ show an obvious accumulation of ${ }^{18} F$ in the frontal lobes and in $(D)$ the cingulate gyrus. Little occipital accumulation of ${ }^{18} \mathrm{~F}$ is apparent in any of the slices of this or the preceeding figure. 


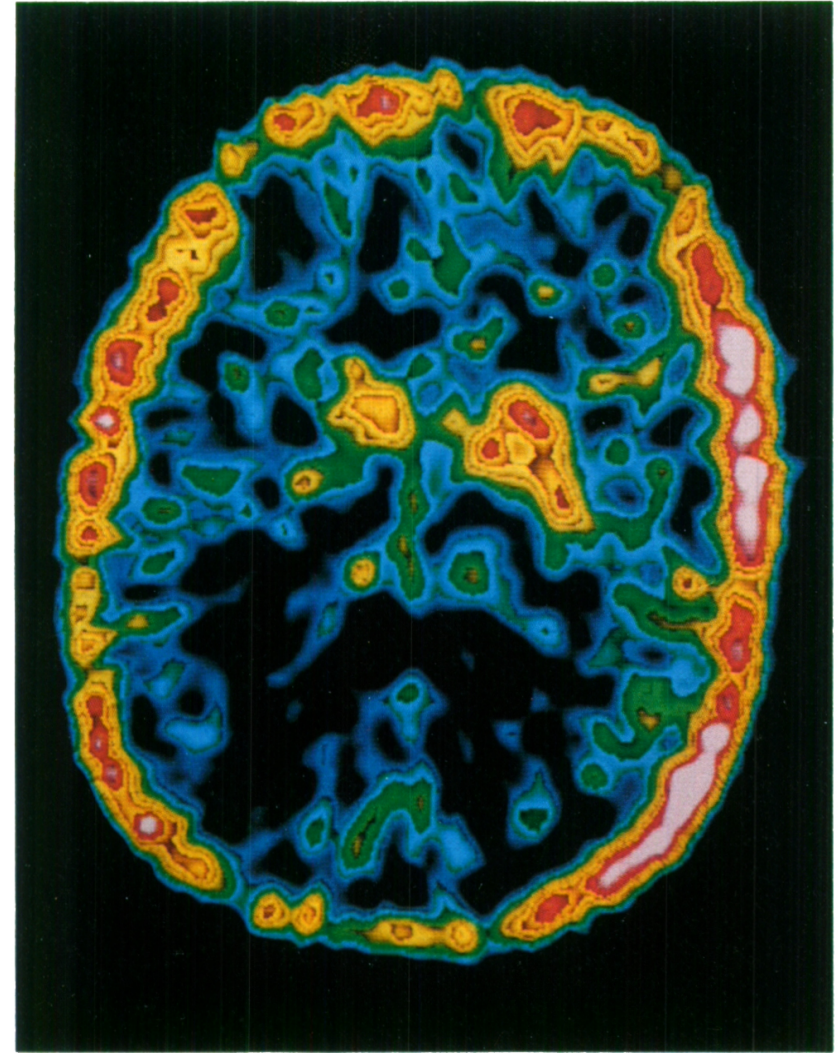

A

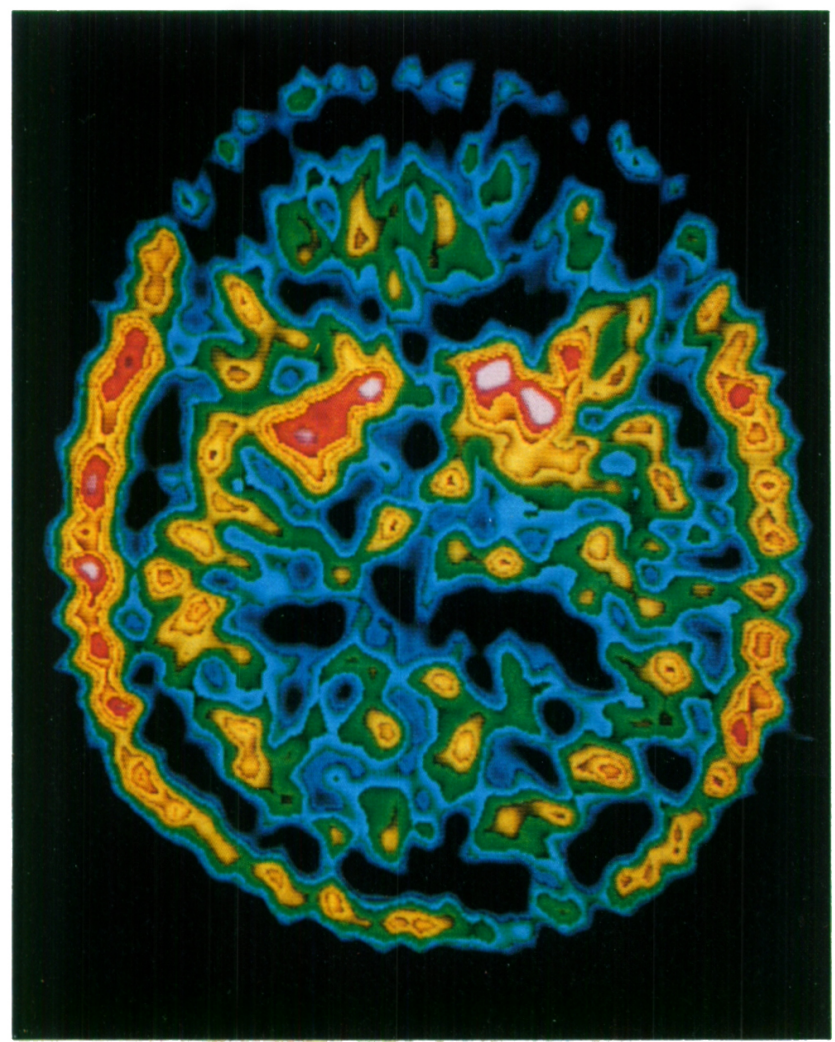

C the right putamen is reduced compared to the left. A less obvious reduction of activity is also seen in the right caudate. When compared to normals the distribution of radioactivity in the left striatum is irregular.

In all figures, the patient's right is represented on the left of the picture.

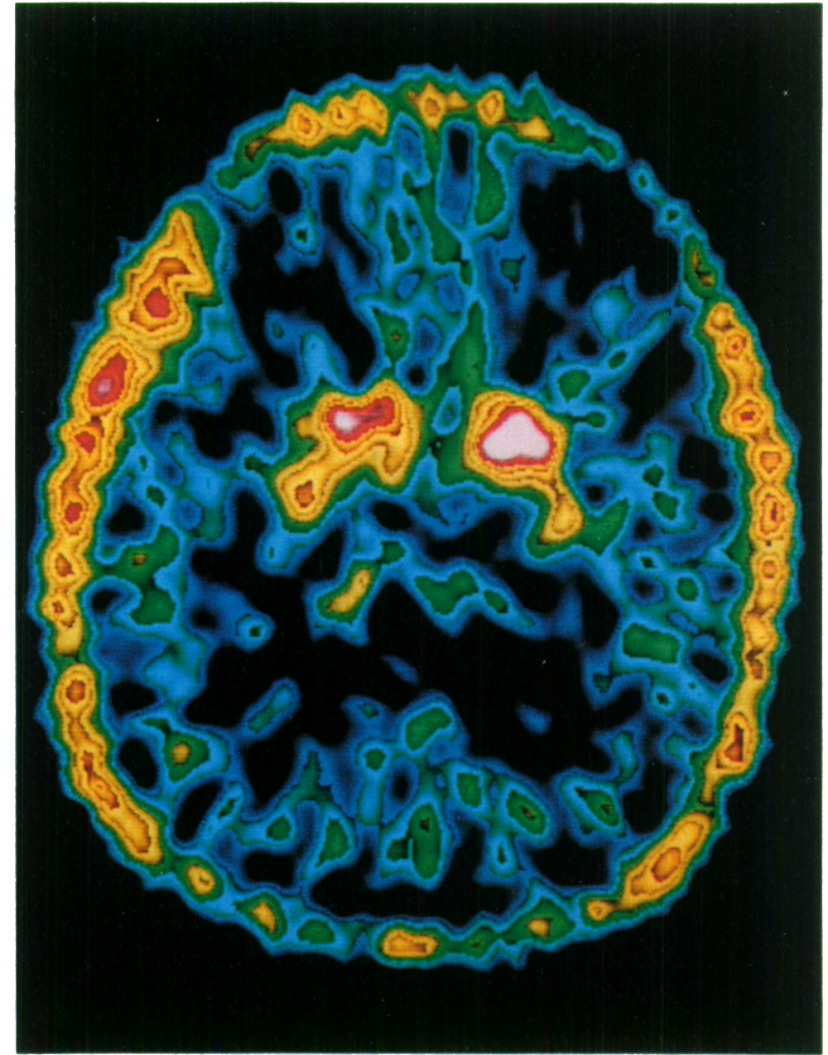

B

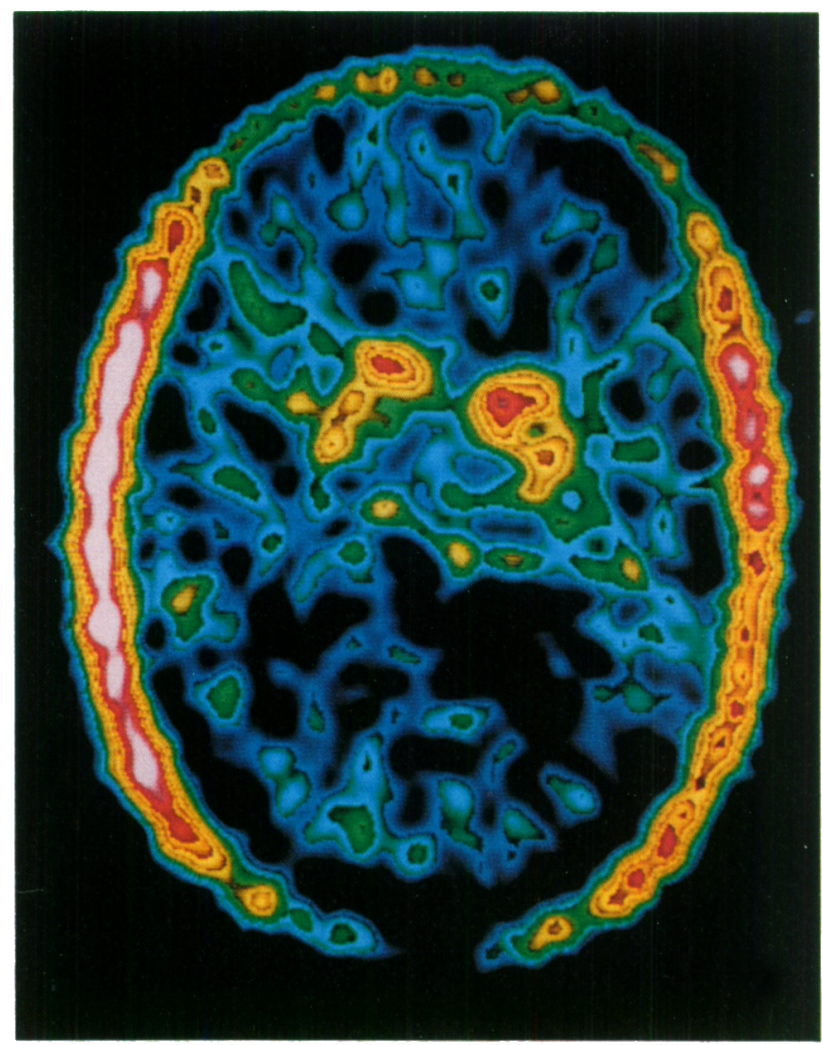

D 


\section{ACKNOWLEDGEMENTS}

Patients were kindly referred by Dr. A.E. Lang (Toronto) and Drs. M. Kronby and A. Talalla (Hamilton). Financial support was received from the Medical Research Council of Canada and from the Parkinson's Foundation. We thank Mr. J. McKay and Dr. J. Kuehner for making accelerator produced fluorine-18 available to us.

\section{REFERENCES}

Firnau G, Garnett ES, Sourkes TL, Missala K (1975) [ ${ }^{18}$ F]Fluoro-dopa: a unique gamma emitting substrate for dopa decarboxylase. Experientia, 31: 1254-1255.

Firnau G, Chirakal R, Sood S, Garnett ES (1981) Radiofluorination with Xenon difluoride: L-6 $\left[{ }^{18}\right.$ F]fluorodopa. J Labelled Com. Radiopharm., 18: 7-8.

Garnett ES, Firnau G, Nahmias C, Chirakal R (1983) Striatal dopamine metabolism in living monkeys examined by positron emission tomography. Brain Res. 280: 169-171.

Garnett ES, Firnau G, Nahmias C (1983) Dopamine visualised in the basal ganglia of living man. Nature, 305: 137-138.

Hokfelt T, Ungerstedt U (1974) The degeneration patterns of the nigrostriatal dopamine system after electrothermic or 6-hydroxydopamine lesions. In Dynamics of Degeneration and Growth in Neurons. Ed. K. Fuxe, L. Olson, Y. Zotterman. Pergammon Press, Oxford

Hornykiewicz O (1980) Biochemical abnormalities in some extrastriatal neuronal systems in Parkinson's disease. In Parkinson's disease; current progress, problems and management. Eds. U.K. Rinne, M. Klingler, G. Stamm, Elsevier, Amsterdam.

Hornykiewicz O (1982) Brain neurotransmitter changes in Parkinson's disease. In Movement Disorders. Eds. C.D. Marsden and S. Fahn. Butterworth Scientific, London.

Lee T, Seeman P, Rajput A et al. (1978) Receptor basis for dopaminergic supersensitivity in Parkinson's disease. Nature 273: 59-61.

Leenders K, Wolfson L, Gibbs J, Wise R, Jones T, Legg N (1983) Regional cerebral blood flow and oxygen metabolism in Parkinson's disease and their response to L-dopa. J. Cereb. Blood Flow Metab., 3: Suppl. 488-489.

Lloyd KG, Hornykiewicz O (1972) Occurrence and distribution of aromatic acid (L-dopa) decarboxylase in human brain. J. Neurochem. 19: 1549-1559.

Lenzi GL, Jones T, Reid J, Moss S (1977) Non-invasive study of the metabolism to blood flow relationship in Parkinson's disease. Acta. Neurol Scand., 56, Suppl. 64: 184-185.

Nahmias C, Firnau G, Garnett ES (1984) Performance characteristics of the McMaster Positron Emission Tomograph. IEEE, NS-31, (in press).

Rougemont D, Baron JC, Collard P, Bustany P, Colmar D, Agid Y (1983) Local cerebal metabolic rate of glucose (CMR G) in treated and untreated patients with Parkinson's disease. J. Cereb. Blood Flow Metab. 3, Suppl. 1: 504-505.

Wiesel FA, Fri CG, Sedvall G (1973) Determination of homovanillic acid turnover in rat striatum using a monoamine oxidase inhibitor. Eur. J. Pharamacol. 23: 104-106.

Wooten GF, Collins RC (1981) Metabolic effects of unilateral lesion of hte substantia nigra. J.Neurosci. 1: 285-291. 